\title{
SECA E SENSORIAMENTO REMOTO: IDENTIFICAÇÃO E MAPEAMENTO NA BACIA HIDROGRÁFICA DO PEIXE - SC ENTRE 2001 E 2010 UTILIZANDO O NDVI
}

\author{
Guilherme Linheira $^{(\mathrm{a})}$, Francisco Henrique de Oliveira ${ }^{(\mathrm{b})}$ \\ (a) Departamento de Geografia, Universidade do Estado de Santa Catarina, glinheira@ @otmail.com \\ (b) Departamento de Geografia, Universidade do Estado de Santa Catarina, chico.udesc@ gmail.com
}

Eixo: GEOGRAFIA FÍSICA E DESASTRES NATURAIS

\begin{abstract}
Resumo
A seca foi o tipo de desastre natural que mais afetou a população brasileira entre 1991 e 2010. Um dos locais que apresentam recorrência deste tipo de fenômeno foi a Mesorregião Oeste Catarinense, no qual está inserida a Bacia Hidrográfica do Peixe. O estudo das secas em Santa Catarina por meio de dados de estações meteorológicas é dificultado pela reduzida quantidade de equipamentos além da restrição de acesso aos dados. Sendo assim, uma das maneiras de se identificar e mapear a ocorrência de secas consiste no uso de dados e técnicas de Sensoriamento Remoto. Sendo assim, este artigo teve como objetivo a identificação e mapeamento da estação do ano onde a seca atingiu a maior extensão na Bacia do Rio do Peixe entre 2001 e 2010. Os resultados obtidos indicaram que o fenômeno atingiu a maior extensão na área de estudo no Verão de 2005 , afetando aproximadamente $30 \%$ da área da bacia. Para esta estação do ano, foi produzida documentação cartográfica temática demonstrando o quadro sinótico estabelecido pelo fenômeno da seca naquela estação.
\end{abstract}

Palavras chave: seca; sensoriamento remoto, NDVI; Bacia do Rio do Peixe.

\section{Introdução}

Embora não causem cenários com ampla destruição de infraestruturas como furacões ou terremotos, as secas são consideradas como o tipo de desastre que mais afeta pessoas em todo o mundo. A amplitude de seus impactos está relacionada principalmente com a necessidade da água para a produção mundial de alimentos, abastecimento humano, dessedentação animal e utilização como insumo em processos industriais diversos (NDMC, 2015). No Brasil, dados oficiais compilados pela Defesa Civil Nacional, indicam que as secas foram os fenômenos motivadores de 50,34\% dos decretos municipais de situação de emergência emitidos entre os anos de 1991 e 2010. Não obstante, foi também a tipologia de desastre que afetou o maior número de pessoas no mesmo período (Defesa Civil Nacional, 2012).

O enfrentamento às secas deve ocorrer com base em princípios básicos de gestão de riscos ambientais. Dentre estes princípios estão a identificação e mapeamento da distribuição espacial do fenômeno de interesse e os períodos do ano com maior probabilidade de ocorrência. Estes processos auxiliam na compreensão da dinâmica estabelecida pelo fenômeno, podendo subsidiar posteriormente o 
direcionamento das ações estruturais e não estruturais que visem à mitigação dos riscos e impactos (Brasil, 2007).

Pesquisas realizadas por Anyamba e Tucker (2005), Berhan et. al (2011), Rulinda et. al (2012) e Souza Júnior et. al (2010), mostraram-se eficientes ao estudar as secas por meio de técnicas de sensoriamento remoto. Dentre as principais vantagens no uso de dados provenientes de satélite, destaca-se a possibilidade de acompanhamento sinótico dos fenômenos do planeta, os amplos bancos de dados disponíveis, além da componente visual extra.

No caso específico do território nacional, os registros da Defesa Civil (2012) indicam como uma das áreas com maior concentração a Mesorregião Oeste Catarinense. Em toda a mesorregião, onde o setor primário é o mais importante na econômica regional, as secas têm causados consideráveis prejuízos socioeconômicos. Destaca-se na região, o território da Bacia Hidrográfica do Rio do Peixe, recorte definido como área de estudo deste trabalho, onde estão inseridos 26 municípios. Somente nesta bacia, entre 2001 e 2010 foram contabilizadas 157 publicações de decretos municipais de situação de emergência em função das secas, evidenciando uma situação-problema recorrente para os municípios da área de estudo.

Apesar da indicação da ocorrência do fenômeno das secas, os dados da Defesa Civil são administrativos, ou seja, não refletem diretamente a situação de qualquer tipo de elemento físico-natural. Sendo assim, estes dados não permitem o reconhecimento da dinâmica espacial das ocorrências das secas e nem a avaliação de seu grau de severidade. Neste caso concreto, dados provenientes de estações meteorológicas também não são adequados para realização das ações citadas, pois no caso específico de Santa Catarina há um limitado número de estações meteorológicas cujos registros não se encontram disponíveis de forma facilitada.

Ante o exposto, depreende-se que o método mais adequado para mapeamentos e avaliações do grau de severidade das secas ocorridas na área de estudo deverá tomar como referência dados e técnicas próprias do Sensoriamento Remoto. Neste sentido, o objetivo principal deste trabalho é identificar a estação do ano em que o fenômeno da seca atingiu a maior extensão na Bacia do Rio do Peixe entre 2001 e 2010 utilizando imagens NDVI do sensor MODIS ${ }^{1}$. Além disso, produzir documentação cartográfica temática com objetivo de mostrar o processo da seca de maneira sinótica durante a estação do ano onde o houve a maior severidade, buscando contribuir para a compreensão da dinâmica envolvendo as secas na área de estudo.

\footnotetext{
${ }^{1}$ MODIS - Moderate Resoluting Imaging Spectroradiometer
} 


\section{OS DESAFIOS DA GEOGRAFIA FÍSICA NA FRONTEIRA DO CONHECIMENTO \\ Instituto de Geociências - Unicamp \\ Campinas - SP \\ 28 de Junho à 02 de Julho de 2017}

\section{Secas e Sensoriamento Remoto: aspectos conceituais}

As secas constituem-se como fenômeno extremamente complexo, fato que impede qualquer disciplina de monopolizar o seu estudo. As secas podem ser simplesmente descritas como sendo um "fenômeno natural temporário de redução das precipitações em determinada região" (NDMC, 2017). Todavia, partindo de uma concepção mais antropocêntrica, as secas deixam de ser um mero fenômeno natural para constituir um fenômeno de natureza socioeconômica. Atualmente, a conceituação mais difundida sobre o termo seca considera que o fenômeno apresenta quatro fases, que se manifestam de forma gradativa e sequencial. Tal definição considera a existência de quatro tipos de seca: seca meteorológica, seca agrícola, seca hidrológica e seca socioeconômica (National Drought Mitigation Center, 2015; World Meteorological Organization, 2011; Mishra e Sigh, 2010; Valiente, 2001).

De forma simplificada a seca meteorológica corresponde ao quadro descrito na definição mais conceitual do termo: um desvio na média de precipitação de determinada área durante determinado tempo. A persistência da ocorrência da seca meteorológica acaba comprometendo a reposição de umidade dos solos, configurando o quadro conceitual da seca agrícola. Vale ressaltar que, caso o solo contenha água suficiente para garantir o desenvolvimento das plantas durante o período de seca meteorológica, não chegará a se produzir a seca agrícola. A configuração da seca agrícola presume a ocorrência de danos para as espécies vegetais (Valiente, 2001).

A persistência da seca agrícola e as falta de reposição de umidade no solo compromete também o sistema de alimentação dos rios e demais corpos hídricos, podendo afetar ou não atividades humanas. Por fim, quando os prejuízos causados pelas secas assumem dimensão generalizada, isto é, em escala regional, configura-se o último estágio do fenômeno, denominado de seca socioeconômica. A figura 01 apresenta as fases da seca e sua evolução em função da duração do evento (Valiente, 2001). 


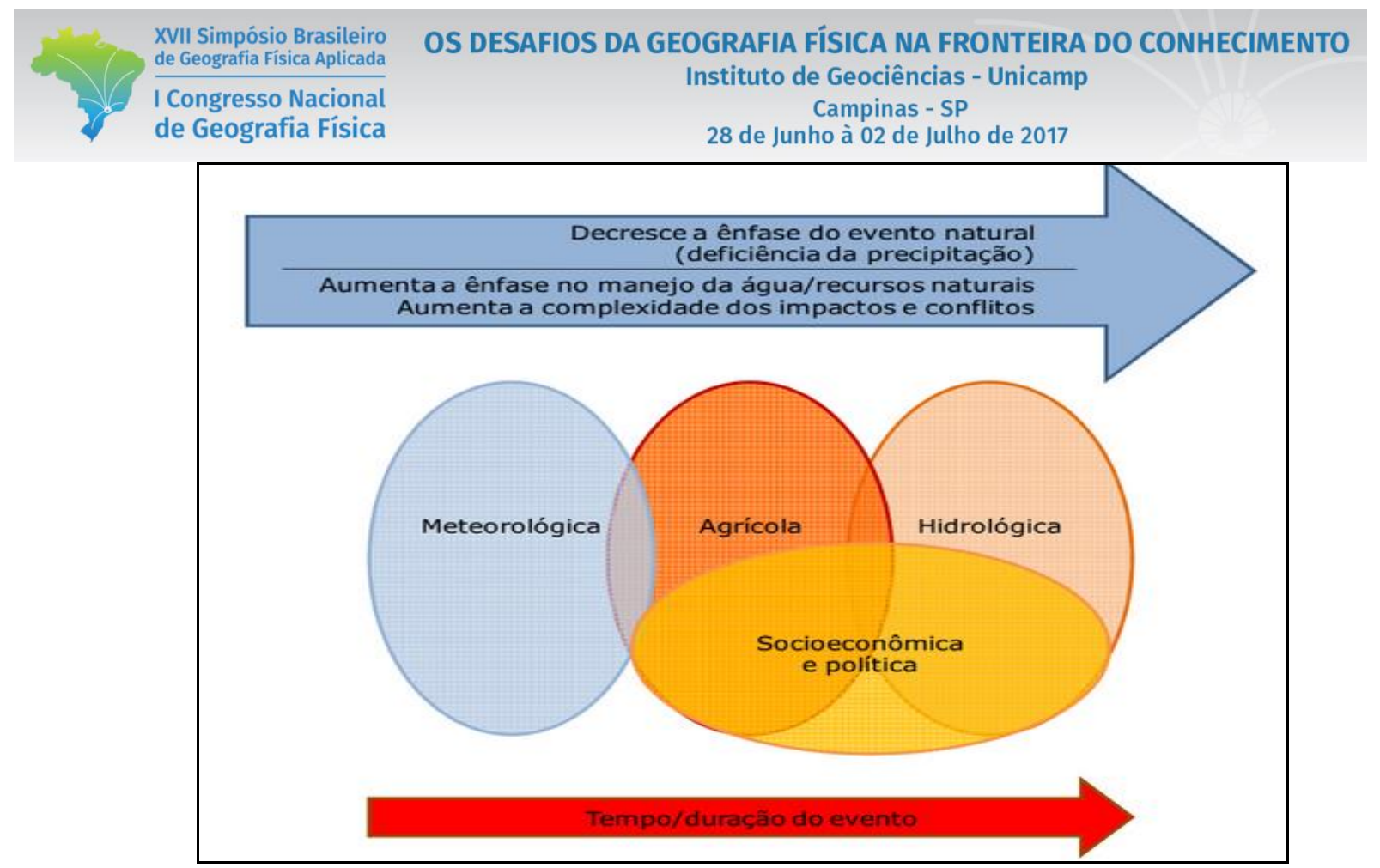

Fig. 1 - Fases da seca em função de sua duração. Fonte: Sousa Junior et al. (2010).

Diante destes aspectos conceituais das secas, depreende-se que os dos dados da superfície terrestre coletados por satélites, são ideais para avaliação e mapeamento da seca em sua fase agrícola. No caso da seca agrícola, a identificação e mapeamento de sua ocorrência acontecem por meio dos obtidos a partir da resposta espectral da vegetação, com participação eventual de dados referentes ao comportamento dos solos. Visando o mapeamento das secas, no ano de 1973 Rouse et. al (1973) desenvolveram o chamado o índice espectral de vegetação denominado Índice de Vegetação por Diferença Normalizada, mais conhecido por sua sigla no idioma inglês - $\mathrm{NDVI}^{2}$. Um índice espectral é o resultado de operações matemáticas entre valores numéricos de pixels das bandas de uma imagem. No caso do NDVI são utilizados dados provenientes das bandas infravermelho (IR) e infravermelho próximo (NIR) das imagens coletadas por sensores específicos como TM e EMT+ do satélite LANDSAT, os sensores AVHRR do Satélite NOAA, os sensores HRV e HRG dos satélites SPOT e o que será utilizado neste estudo o sensor MODIS dos satélites AQUA e TERRA. A utilização deste índice tem como objetivo ressaltar a resposta da vegetação, aumentando a sensibilidade de sua resposta.

Rosa (2007) argumenta que o NDVI detém a habilidade para minimizar efeitos topográficos ao produzir uma escala linear de medida. Os pixels da imagem NDVI podem variar na escala entre +1 e -1 , onde os valores mais próximos de 1 representam a maior densidade de cobertura vegetal, enquanto valores próximos a 0 representa superfícies não-vegetadas e os valores negativos representam as nuvens. As

\footnotetext{
${ }^{2}$ Normalized Difference Vegetation Index
} 
variações nos valores observados no NDVI estão relacionadas principalmente ao vigor da vegetação, ao percentual de cobertura verde e a biomassa da vegetação, que por sua vez, tem relação com a disponibilidade hídrica no ambiente.

É fundamental destacar que, no caso das secas, a utilização de apenas uma imagem NDVI não é suficiente para sua caracterização, necessitando de uma comparação com uma imagem de referência ou com uma série histórica por meio de modelos estatísticos específicos (Rulinda et al., 2012).

Ao consultar a bibliografia relacionada ao uso do NDVI para caracterização das secas, evidenciou-se a existência de diferentes modelos estatísticos aplicados por Anyamba e Tucker (2005), Berhan et. al (2011), Rulinda et. al (2012). Dentre as diferentes possibilidades de modelos, destaca-se o modelo denominado Deviation NDVI, proposto por Berhan (2011), expresso na seguinte equação:

\section{Dev_NDVI $=$ NDVI_i - NDVI_mean_i}

Onde, Dev_NDVI refere-se às anomalias identificadas, NDVI_i refere-se aos valores NDVI do período analisado e NDVI_mean_i refere-se a média do período analisado para a série histórica utilizada. Em termos práticos, os valores negativos (DEV_NDVI < 0) referem-se a uma condição de redução da biomassa vegetal, enquanto que os valores positivos (DEV > 0) referem-se a uma condição de ampliação da biomassa da vegetação para o período de análise.

\section{Materiais e Métodos}

\section{1 Área de estudo}

A Bacia do Rio do Peixe está localizada no estado de Santa Catarina, na região administrativa denominada de Mesorregião Oeste Catarinense, com 26 municípios inseridos na bacia, totalizando uma área de $5.238 \mathrm{~km}^{2}$. Conta com uma população de 262 mil habitantes, sem grandes aglomerações urbanas, sendo Caçador o maior município em termos populacionais com 67 mil habitantes. O produto interno bruto (PIB) da Bacia atinge o montante de 4,56 bilhões de reais, em que o valor per capita atinge $\mathrm{R} \$ 14.188,00$, superior à média catarinense, com o valor de $\mathrm{R} \$ 11.100,00$. Destacam-se na economia da Bacia do Rio do Peixe a agropecuária e as agroindústrias frigoríficas, as indústrias de madeira e mobiliário, de papel e celulose, fruticultura e vinicultura, lacticínios e metal mecânica. Do ponto de vista da População Economicamente Ativa, 43\% concentram-se nas atividades relativas à agropecuária, outros $40 \%$ estão no setor de Serviços, enquanto que os demais $17 \%$ estão nas atividades industriais. Sendo assim, percebe-se que as atividades agropecuárias são de grande importância na região, cujo modelo continua sendo, 


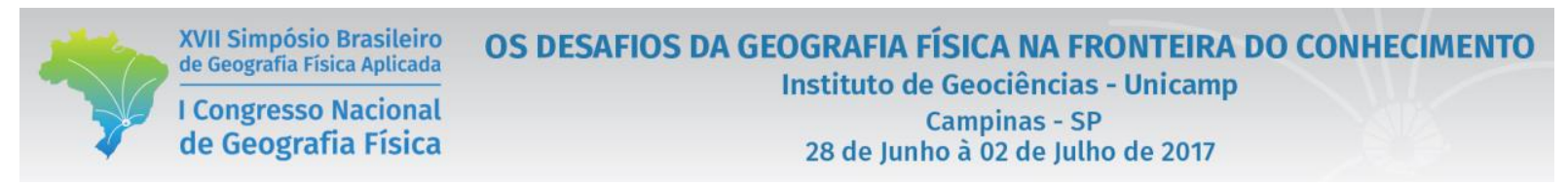

predominantemente, de agricultura familiar de pequena propriedade e com atividades diversificadas (Zago e Paiva, 2008).

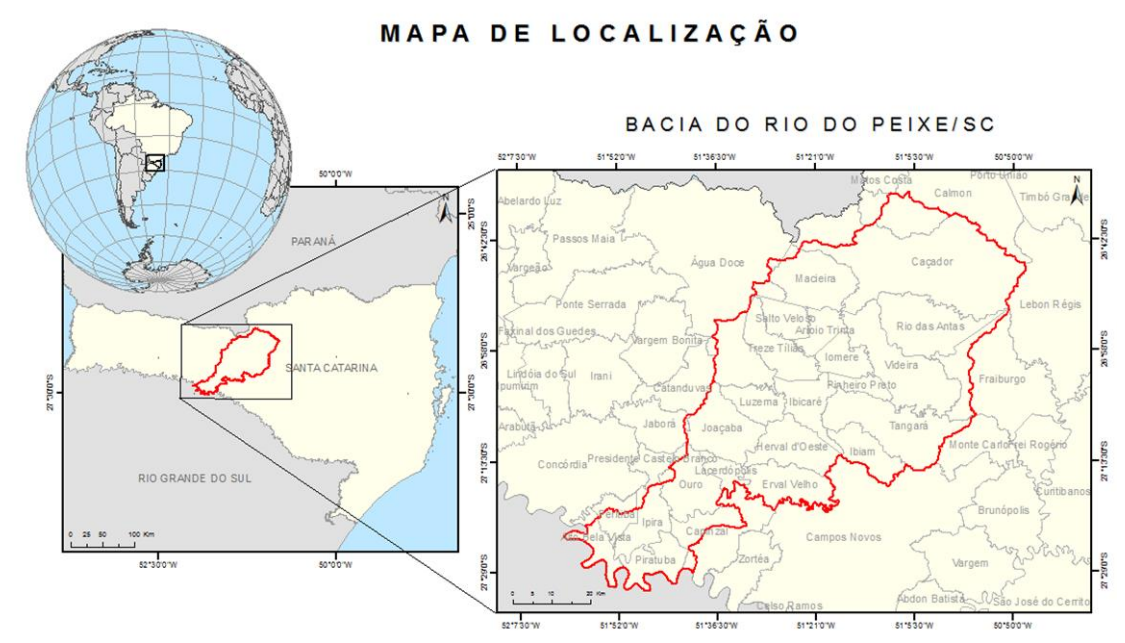

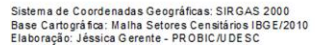

Fig. 2 - Localização da área de estudo.

\subsection{Procedimentos metodológicos}

A pesquisa teve início com o processo de aquisição dos dados de interesse. Neste caso, optou-se por trabalhar com o produto denominado MOD13Q1 ${ }^{3}$, derivado do sensor MODIS, obtidos por meio do sítio eletrônico Land Processes - Distributed Active Archive Center/NASA (https://lpdaac.usgs.gov/), escolhido devido à sua distribuição gratuita e online. O produto apresenta resolução temporal de 16 dias e resolução espacial de 250 metros. Seu nível de processamento é o L3, que significa que o dado está geométrica e radiometricamente calibrado. Ao todo foram adquiridas 231 imagens correspondendo a uma série temporal de 10 anos: 2001 a 2010, período definido de acordo com a disponibilidade de dados de forma gratuita. Como a área de estudo corresponde ao sul do Brasil, o recorte das imagens corresponde à área designada pelo código H13V11 (referente à localização da área na matriz de imagens do MODIS). Como os produtos MODIS são adquiridos em escala global e possuem formato e projeção não usuais, alguns pré-processamentos foram necessários. Todos os procedimentos foram realizados no software ArcMAP 10.2, licenciado em nome do GeoLab/UDESC.

\footnotetext{
${ }^{3}$ Maiores detalhes sobre as características técnicas do produto MOD13Q1 podem ser encontradas no sítio eletrônico: https://lpdaac.usgs.gov/dataset_discovery/modis/modis_products_table/mod13q1
} 
Como o produto MOD13Q1 consiste em um pacote com 12 camadas de dados, o primeiro procedimento realizado na etapa de pré-processamento consistiu na extração do subproduto desejado. No caso desta pesquisa, foi extraída a camada referente aos dados NDVI, eliminando-se as demais camadas. Posteriormente os arquivos extraídos foram convertidos do formato HDF para o formato GeoTiff. Diante do alto número de imagens, foi criada uma rotina de automatização para a conversão do formato com a ferramenta "ModelBuilder", utilizada também para efetuar o recorte da área de e a multiplicação pelo fator de escala em todas as 231 imagens.

Por fim, foi realizada a multiplicação das imagens pelo fator de escala do NDVI, pois os dados originais possuem uma ordem de grandeza de -2000 a 10000. Após este procedimento os valores dos pixels da imagem tiveram seus valores alterados para a escala própria deste índice de vegetação, que varia de -1 a +1 . Ao fim do pré-processamento foram obtidos os produtos específicos com os dados do NDVI já na escala normalizada, ou seja, prontos para a etapa de processamento.

Já na etapa de processamento, o primeiro procedimento foi o estabelecimento de uma única imagem média (pixel a pixel) para maioria dos meses da série histórica, pois contavam com duas imagens coletadas no mesmo mês. Com isso, o número de imagens foi reduzido das 231 iniciais para 120. O mesmo procedimento de obtenção de média citado anteriormente, foi aplicado para cada mês do ano, obtendo-se, portanto, uma imagem do mês de Janeiro composta pela média dos valores dos pixels nas imagens de Janeiro de 2001, Janeiro de 2002, Janeiro de 2003, e assim por diante. O estabelecimento destas imagens médias de cada mês é fundamental para analisar as imagens NDVI por meio da aplicação do modelo estatístico denominado "Deviation NDVI” (Berhan et. al, 2011).

Após a obtenção de uma imagem de referência para cada mês do ano o modelo estatístico Deviation NDVI foi processado por meio da ferramenta Raster Calculator do software ArcMAP 10.2. IG. A figura 03 demonstra os processos matricias realizados no modelo para geração da imagem de saída Deviation NDVI. As cores foram utilizadas para exemplificar a classificação dos resultados obtidos, onde os tons de vermelho e laranja indicam a redução da produção de fitomassa, enquanto os tons de verde indicam seu aumento. 

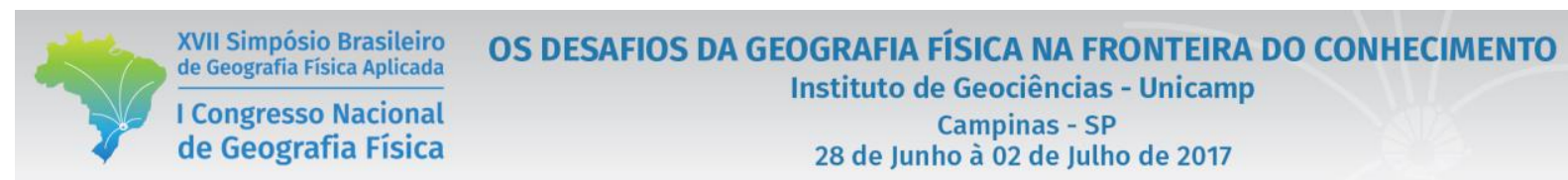

Input 1) Imagem
Analisada (NDVI Mensal)
\begin{tabular}{|c|c|c|c|}
\hline 0.7 & 0.2 & 1.0 & 0.7 \\
\hline 0.1 & 0.5 & 0.5 & 0.2 \\
\hline 0.3 & 0.2 & 0.5 & 0.7 \\
\hline 0.7 & 0.4 & 0.2 & 0.8 \\
\hline
\end{tabular}

NDVIAbril 2005
Input 2) Imagem

Referência (NDVI Médio

Mensal)

\begin{tabular}{|c|c|c|c|}
\hline 0.5 & 0.4 & 0.8 & 0.2 \\
\hline 0.3 & 0.5 & 0.1 & 0.3 \\
\hline 0.7 & 0.6 & 0.8 & 0.5 \\
\hline 0.9 & 0.2 & 0.4 & 1.0 \\
\hline
\end{tabular}

NDVIMÉDIO-ABRIL

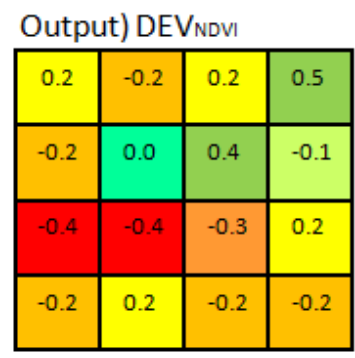

Fig. 03 - Exemplo de aplicação do modelo estatístico Deviation NDVI. Fonte: Montibeller, 2014

A atribuição de cores no exemplo apresentado tomou como referência a tabela (tabela I) de intervalos de valores para classificação de dados Deviation NDVI, proposta por Berhan et. al (2011). Estes intervalos foram utilizados para reclassificação das imagens Deviation NDVI obtidas, possibilitando a quantificação da extensão da seca.

\begin{tabular}{|c|c|c|}
\hline $\mathrm{N}^{\mathrm{o}}$ & Classes & Intervalo de valores do Deviation NDVI \\
\hline 1 & Seca extrema & $<=-0.2$ \\
\hline 2 & Seca moderada & $>-0.2 A N D<=-0.05$ \\
\hline 3 & Normal & $>0.1$ \\
\hline 4 & Ótimo & $>=0.1$ \\
\hline
\end{tabular}

Tabela I - Classes e valores para classificação dos dados provenientes do modelo estatístico Deviation NVDI.

Após este procedimento, foram obtidas 120 imagens reclassificadas nas quatro classes elencadas na tabela I. No software ArcMAP 10.2, foi realizada a extração dos número de pixels pertencente a cada classe da tabela de atributos de cada uma das imagens, sendo posteriormente sistematizados em planilha eletrônica. Após este processo, foi construída uma tabela contendo todos os meses da série histórica com a quantidade de pixels em cada uma das classes. Como o parâmetro temporal de análise desta pesquisa foi a estação do ano, foram extraídos os valores médios para cada estação do ano da série histórica. Com isso, busca-se também, eliminar possíveis ruídos existentes, como influências atmosféricas, nos dados coletados por satélite. Por fim, após a análise dos dados e identificação da estação onde a ocorrência de seca foi mais intensa, foi realizada a elaboração da documentação cartográfica temática de interesse. No documento cartográfico elaborado foram utilizados também dados referentes aos decretos de situação de emergência emitidos pelos municípios da área de estudo durante o período representado. Estes dados foram obtidos no portal S2ID (https://s2id.mi.gov.br/) da Defesa Civil Nacional. 


\section{Resultados}

O processamento das imagens com o modelo estatístico Deviation NDVI e a posterior reclassificação em quatro classes (ótimo, normal, seca moderada e seca extrema) permitiu avaliar comparativamente a incidência de seca e sua extensão na área de estudo durante as estações do ano entre 2001 e 2010. A avaliação dos resultados indicou que o Verão de 2005 foi o período onde a classe "seca moderada" selecionada como parâmetro comparativo de análise entre as estações - atingiu a maior extensão da área de estudo, com 29,56\%. Houve ainda, outras três estações onde a extensão da classe "seca moderada" superou a casa dos 20\%: Outono de 2009 com 22,73\%; Outono de 2010 com 21,30\% e Inverno de 2009 com 21,02\%. Registra-se ainda, a ocorrência de 15 estações onde a classe "seca moderada" afetou mais que $10 \%$ e menos que $20 \%$ da área de estudo, evidenciando a recorrência do fenômeno na série histórica analisada.

Para o Verão de 2005 foi realizada a elaboração de documentação cartográfica temática (figura 04) mostrando a evolução das classes nos meses dessa estação. Na documentação elaborada consta ainda indicação das decretações de situação de emergência emitidas pelos municípios inseridos na área de estudo em cada um dos meses do período representado.

Ao analisar especificamente o Verão de 2005, evidencia-se que em Janeiro a classe seca moderada representava 11,43\% da área de estudo. Neste mesmo mês, dados da Defesa Civil indicaram a emissão de decretos de situação de emergência por parte de 06 municípios inseridos na área de estudo. Este fato mostra que no mês de Janeiro o processo de seca já havia sido deflagrado na área de estudo, intensificando-se posteriormente conforme mostra o material cartográfico.

Já no mês de Fevereiro houve um aumento significativo na classe seca moderada, que saltou para 33,81\% da área de estudo. Neste mesmo mês, foram emitidas 15 decretações de situação de emergência por parte dos municípios da área de estudo. Em Março, a classe seca moderada aumentou novamente, atingindo 43,46\% da área de estudo. Outros 03 municípios efetuaram a decretação de situação de emergência em Março, sendo que, somado aos registros de Janeiro e Fevereiro, todos os municípios da área de estudo efetuaram a decretação. Do ponto de vista da distribuição espacial das secas, não foi possível identificar no período analisado nenhum tipo de padrão ou concentração dos pixels representantes da classe "seca moderada".

A identificação do Verão de 2005 como a estação com maior incidência de seca na Bacia do Rio do Peixe corresponde aos resultados obtidos por Souza Junior et. al (2012) que estudou as secas em toda a região Sul do Brasil entre 2001 e 2012, utilizando o EVI - Enhanced vegetation Index. Outro estudo com resultados similares ao desta pesquisa foi o realizado por Montibeller (2014), utilizando o NDVI em toda a Mesorregião Oeste Catarinense entre 2001 e 2010. 


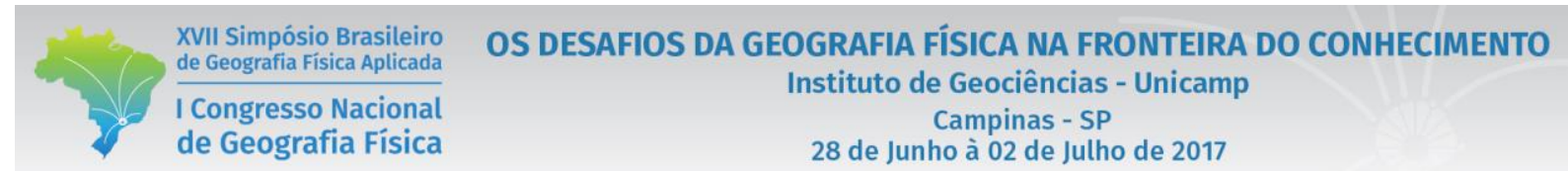

Portanto, conclui-se que o método proposto e aplicado é válido para identificação e mapeamento da dispersão do fenômeno da seca na área de estudo. Sugere-se a replicação do método para outras áreas de estudo visando sua validação bem como a aplicação de outros índices espectrais na área de estudo deste trabalho.

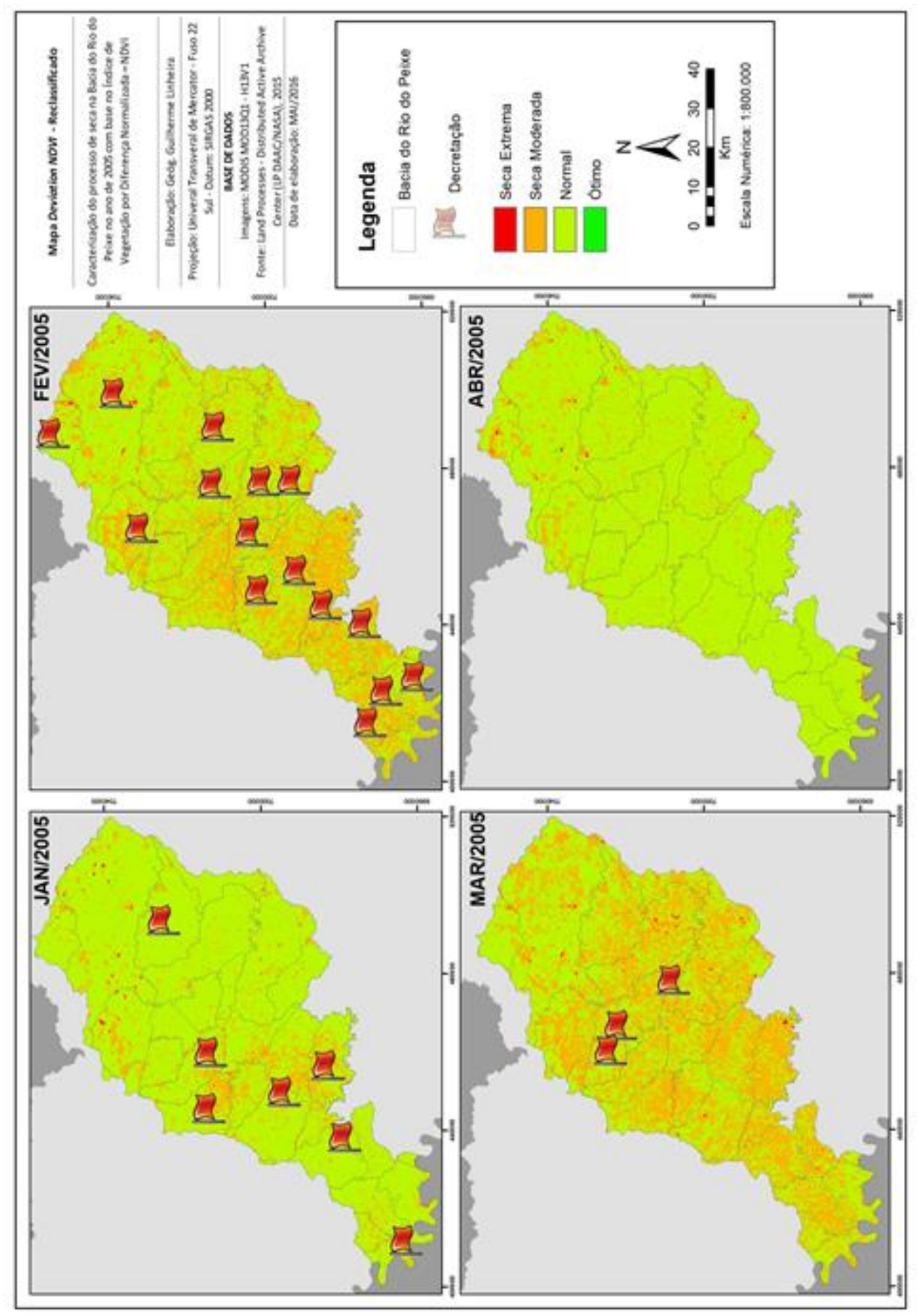




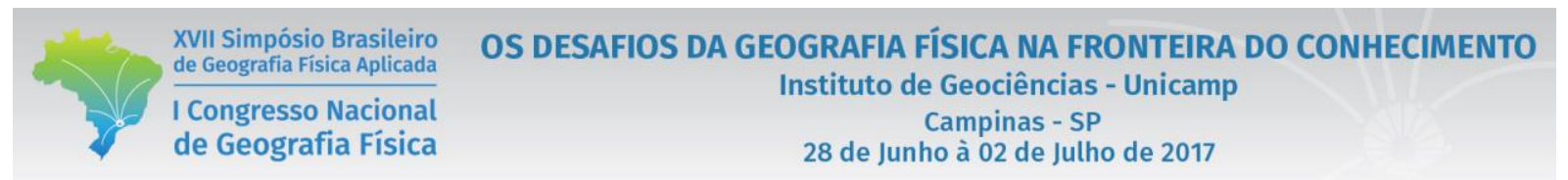

Fig. 05 - Mapa Deviation NDVI reclassificado do Verão de 2005 na Bacia do Rio do Peixe, SC 


\section{Bibliografia}

ANYAMBA, A.; TUCKER, C. J.. Analysis of Sahelian vegetation dynamics using NOAA-AVHRR NDVI data from 1981-2003.Journal Of Arid Environments. Austin, p. 596-614. jan. 2005.

BERHAN, G.; HILL, S.; TADESSE, T.; ATNAFU, 20011. Using satelitte images for drought monitoring: A knowledge discovery approach. Journal Of Strategic Innovation And Sustainability. West Palm Beach, p. 135153. jan. 2011.

BRASIL. Centro Universitário de Estudos e Pesquisa Sobre Desastres. Universidade Federal de Santa Catarina. Atlas de Desastres Naturais 1991 - 2010: Volume Brasil. Florianópolis: Ceped, 2012. 94 p. Disponível em: <http://150.162.127.14:8080/atlas/atlas.html>. Acesso em: 18 abr. 2014.

BRASIL. Ministério das Cidades / Instituto de Pesquisas Tecnológicas - IPT. Mapeamento de Riscos em Encostas e Margem de Rios- Brasília: Ministério das Cidades; Instituto de Pesquisas Tecnológicas - IPT, 2007.

MISHRA, Ashok K.; SINGH, Vijay P.. A review of drought concepts. Journal Of Hydrology. Austin, p. $202-216$. 02 fev. 2010.

MONTIBELLER, Á. G.. Potencial do sensoriamento remoto aplicado ao monitoramento da seca no Oeste de Santa Catarina. 2014. 120 f. TCC (Graduação) - Curso de Geografia, Faed, Universidade Estadual de Santa Catarina, Florianópolis, 2014.

NATIONAL DROUGHT MITIGATION CENTER - NDMC. What's is drought? Nebraska, 2015.

PRATHUMCHAI, K.; HONDA, Kiyoshi; NUALCHAWEE, Kaew. Drought risk evaluation using remote sensing and GIS: a case study in Lop Buri Province. In: Paper presented at the 22nd Asian Conference on Remote Sensing. 2001. p. 9

ROSA, Roberto. Introdução ao Sensoriamento Remoto. 6. ed. Uberlândia: Edufu, 2007. 248 p.

ROUSE, J. W., R. H. Haas, J. A. Schell, and D. W. Deering (1973). Monitoring vegetation systems in the Great Plains with ERTS, Third ERTS Symposium, NASA SP-351 I, 309- 317.

RULINDA, Coco Gratia. Assessing vegetative drought from multi-temporal NDVI images. 2012.175 f. Dissertação (Mestrado) - Curso de Geoinformation Science And Earth Observations, University Of Twente, Kishasa, 2012.

SOUSA JUNIOR, M. A.; PARDI LACRUZ, M.S; SAUSEN, T. M.; COSTA, L. F. F.; PEREIRA, R. S.. Estiagem na Região Sul do Brasil - Caracterização por meio de Imagens EVI/MODIS. In: I Congresso Brasileiro sobre Desastres Naturais, 2012, Rio Claro. I Congresso Brasileiro sobre Desastres Naturais, 2012.

SOUSA JUNIOR, M. A.; SAUSEN, T. M.; PARDI LACRUZ, M. S. Monitoramento de estiagem na região sul do Brasil utilizando dados EVI/MODIS no período de dezembro de 2000 a junho de 2009; INPE-16682-TDI/1627, São José dos Campos, SP, 2010.

VALIENTE, Óscar Marcos. Sequía: Definiciones, tipologías y métodos de cuantificación. Investigaciones Geográficas, Barcelona, v. 2001, n. 26, p.59-80, mar. 2001.

ZAGO, S.; PAIVA, D. P de (Org.). Rio do Peixe: Atlas da Bacia Hidrográfica. Joaçaba: Unoesc, 2008.138 p.

WORLD METEOROLOGICAL ORGANIZATION - WMO. United Nations (Org.). Integrated Drought Management Programme: Concept Note. 2011. 